\title{
Development of Multifunctional Pullulan/Chitosan-Based Composite Films Reinforced with ZnO Nanoparticles and Propolis for Meat Packaging Applications
}

\author{
Swarup Roy ${ }^{+}\left(\mathbb{D}\right.$, Ruchir Priyadarshi ${ }^{+}(\mathbb{D}$ and Jong-Whan Rhim *(i) \\ Department of Food and Nutrition, BioNanocomposite Research Center, Kyung Hee University, \\ 26 Kyungheedae-ro, Dongdaemun-gu, Seoul 02447, Korea; swaruproy2013@gmail.com (S.R.); \\ ruchirpriyadarshi@gmail.com (R.P.) \\ * Correspondence: jwrhim@khu.ac.kr \\ + Both authors contributed equally to this work.
}

Citation: Roy, S.; Priyadarshi, R.; Rhim, J.-W. Development of Multifunctional

Pullulan/Chitosan-Based Composite

Films Reinforced with $\mathrm{ZnO}$

Nanoparticles and Propolis for Meat Packaging Applications. Foods 2021, 10, 2789. https://doi.org/10.3390/ foods10112789

Academic Editors: Matteo

Alessandro Del Nobile and Amalia Conte

Received: 28 October 2021

Accepted: 9 November 2021

Published: 12 November 2021

Publisher's Note: MDPI stays neutral with regard to jurisdictional claims in published maps and institutional affiliations.

Copyright: (C) 2021 by the authors Licensee MDPI, Basel, Switzerland. This article is an open access article distributed under the terms and conditions of the Creative Commons Attribution (CC BY) license (https:// creativecommons.org/licenses/by/ $4.0 /)$

\begin{abstract}
Pullulan/chitosan-based multifunctional edible composite films were fabricated by reinforcing mushroom-mediated zinc oxide nanoparticles (ZnONPs) and propolis. The ZnONPs were synthesized using enoki mushroom extract and characterized using physicochemical methods. The mushroom-mediated ZnONPs showed an irregular shape with an average size of $26.7 \pm 8.9 \mathrm{~nm}$. The combined incorporation of ZnONPs and propolis pointedly improved the composite film's UV-blocking property without losing transparency. The reinforcement with ZnONPs and propolis improved the mechanical strength of the pullulan/chitosan-based film by $\sim 25 \%$. Additionally, the water vapor barrier property and hydrophobicity of the film were slightly increased. In addition, the pullulan/chitosan-based biocomposite film exhibited good antioxidant activity due to the propolis and excellent antibacterial activity against foodborne pathogens due to the ZnONPs. The developed edible pullulan/chitosan-based film was used for pork belly packaging, and the peroxide value and total number of aerobic microorganisms were significantly reduced in meat wrapped with the pullulan/chitosan/ZnONPs/propolis film.
\end{abstract}

Keywords: enoki mushroom; ZnONPs; propolis; pullulan/chitosan; antibacterial; antioxidant activity; meat packaging

\section{Introduction}

Currently, food spoilage is a growing concern of the global food industry, and food spoilage has a significant impact on food supply and demand. The main cause of food quality degradation due to the oxidation and deterioration of food is the contamination and proliferation of micro-organisms during food storage. Such food spoilage has significantly impacted the quality and safety of perishable foods, especially animal products, due to the high fat content of meat products. In recent years, the intake of processed meat products has been very high, causing a serious spoilage problem in production and consumption. According to reports, $\sim 23 \%$ of meat produced is lost or wasted [1]. As consumers demand safe food, there is a growing interest in developing and using edible packaging to preserve meat quality to keep food safe and extend its shelf life [2]. The most important challenge in this situation is to manufacture suitable packaging materials that can extend the shelf life of food. For this purpose, active packaging with antibacterial/antioxidant functions is emerging as one of the tools to control the deterioration of food [3-5].

Active packaging has an advantage over the direct use of antioxidant/antibacterial ingredients in foods because this type of packaging allows for the controlled release of active ingredients from the food packaging surface [6-8]. In this regard, renewable and degradable bio-based polymers of natural origin are suitable candidates to replace synthetic plastics in reducing environmental pollution [9-11]. Currently, various bio-based 
polymers such as polysaccharides and proteins are being studied. Although they have disadvantages such as low strength and gas barrier properties, they attract great attention as substitutes for petroleum-based plastics [12-14]. Another way to address the limitations of bio-based polymer matrices is to combine biopolymers to create blend films or to create composite materials with functional nanofillers or bioactive compounds [15-19]. For this, the blend of pullulan and chitosan can be an ideal choice as a solid base polymer matrix. Both pullulan and chitosan are edible polysaccharide-based biopolymers known for their excellent film-making potential. Additionally, previous reports have shown that these combinations create a highly compatible film that compensates for the imperfections of each matrix [20-24].

Nanofillers and bioactive natural ingredients are known to enhance the functional properties (antimicrobial and antioxidant) of active packaging films. As one of the commonly used nanofillers, zinc oxide nanoparticles (ZnONPs) are generally recognized as safe (GRAS) to be used in the food sector [25-28]. Adding ZnONPs improves the antimicrobial properties and helps enhance the physical properties, like the mechanical and water vapor barrier properties, of the packaging films [29-31]. As a potential antioxidant filler, the bioactive natural compound propolis plays a useful role due to its flavonoids, essential oils, waxes, and pollen [32-35]. Propolis is a complex mixture mainly obtained from honey bees, and it is a well-known, naturally occurring multifunctional material used since ancient times. The combination of nanofillers ( $\mathrm{ZnONPs}$ ) and natural bioactive compound (propolis) can be a good combination to enhance the physical and functional properties of edible active packaging films. A combination of antibacterial/antioxidant functional fillers in bio-based packaging films can be particularly useful to control the spoilage of meat products.

Therefore, the current work aimed to fabricate multifunctional active packaging films based on a pullulan/chitosan blend film integrated with ZnONPs and propolis. The pullulan/chitosan-based composite film was prepared, the film properties were characterized using analytical methods, and film's applicability to pork loin packaging was tested.

\section{Materials and Methods}

\subsection{Materials}

The pullulan was procured from Korea Bio Polymer Co. Ltd. (Bucheon, Gyeonggi-do, Korea). The zinc chloride, potassium hydroxide, and glycerol were acquired from Daejung Chemicals \& Metals Co., Ltd. (Siheung, Korea). The chitosan (viscosity: 200-800 cP at $1 \%$ acetic acid, MW: 190,000-310,000 based on viscosity, degree of deacetylation: 75-85\%), 2,2-diphenyl-1-picrylhydrazyl, 2,2'-azino-bis (3-ethylbenzothiazoline-6-sulfonic acid), and potassium persulfate were purchased from Sigma-Aldrich (St. Louis, MO, USA). The alcoholic extracts of propolis and enoki mushrooms were procured from a local supermarket in Seoul, Korea.

\subsection{Preparation of Mushroom-Mediated $\mathrm{ZnONP}$}

For the preparation of the ZnONPs, the enoki mushroom extract (ME) was first prepared. For this, $10 \mathrm{~g}$ of enoki mushroom was cut into tiny pieces, mixed with $100 \mathrm{~mL}$ of DI water, heated at $80^{\circ} \mathrm{C}$ for $10 \mathrm{~min}$ while being stirred at $500 \mathrm{rpm}$, and then cooled to room temperature. The undissolved solids were removed by centrifugation at $5000 \mathrm{rpm}$ for $15 \mathrm{~min}$. The collected extract was stored at $-20^{\circ} \mathrm{C}$ until further use [36,37]. A total of $6.8 \mathrm{~g}$ of $\mathrm{ZnCl}_{2}$ was added $(0.1 \mathrm{M})$ to $500 \mathrm{~mL}$ of $10 \% \mathrm{ME}$, mixed well, and heated until the temperature reached $70{ }^{\circ} \mathrm{C}$. Then, $500 \mathrm{~mL}$ of $\mathrm{KOH}$ solution $(0.2 \mathrm{M})$ was slowly added to the mixture with vigorous agitation for one hour. The white principate formed was collected by filtration, and the filtrate was washed with DI water until it reached a $\mathrm{pH}$ of 7 and then dried at $50{ }^{\circ} \mathrm{C}$ overnight to attain powdered ZnONPs. 


\subsection{Preparation of Pullulan/Chitosan-Based Films}

The pullulan/chitosan-based film was prepared using a solution casting method [22], as presented in Scheme 1. For this, $1.5 \mathrm{~g}$ of chitosan was dissolved in $100 \mathrm{~mL}$ of $1 \%$ acetic acid solution with vigorous stirring. A total of $1.5 \mathrm{~g}$ of pullulan was dissolved in $100 \mathrm{~mL}$ of DI water by heating it at $70{ }^{\circ} \mathrm{C}$ with continuous agitation. Then, the chitosan and pullulan solutions were mixed, glycerol $0.9 \mathrm{~g}$ ( $30 \mathrm{wt} \%$ of polymer) was added, and then $0.08 \mathrm{~g}$ of ZnONPs and $0.2 \mathrm{~g}$ of propolis ( 2 and $5 \mathrm{wt} \%$ based on biopolymer, respectively) were added with vigorous stirring. The film-forming solutions were cast on Teflon film-coated glass plates. The dried films were conditioned at $25^{\circ} \mathrm{C}$ and $50 \% \mathrm{RH}$ for $72 \mathrm{~h}$. For evaluation, neat films of pullulan/chitosan, pullulan/chitosan/ZnONPs, and pullulan/chitosan/propolis were also fabricated following an identical process. The prepared films were designated as PLN/CTS, PLN/CTS/ZnO, PLN/CTS/PPS, and PLN/CTS/ZnO/PPS, respectively, depending on the composite materials.

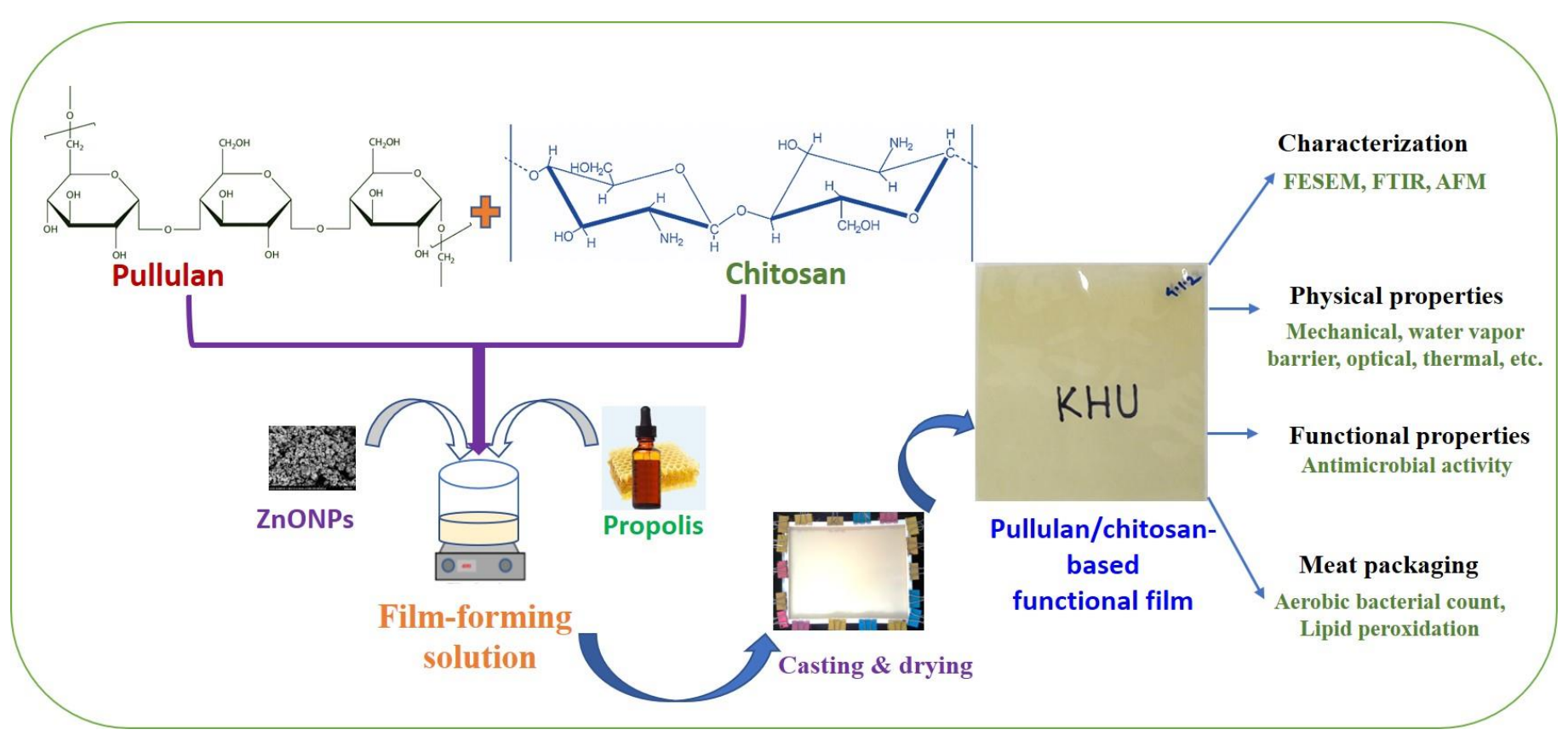

Scheme 1. Schematic presentation for the fabrication of pullulan/chitosan-based biocomposite films.

The details of the characterization methods of mushroom-mediated ZnONPs and the biocomposite films are provided in Supporting Information.

\section{Results and Discussion}

\subsection{Characterization of $\mathrm{ZnONPs}$}

The appearance of white residue demonstrated the formation of ZnONPs. The formation of ME-capped ZnONPs was examined by the UV-vis spectra (Figure 1a), and the results showed a clear, typical absorption band around $350 \mathrm{~nm}$ due to the ZnONPs. The XRD patterns of the ZnONPs (Figure 1b) showed a distinctive pattern of diffraction peaks at (110), (002), (100), (102), (110), (103), (201), (004), and (202), representing the crystalline ZnONPs. The obtained results are well matched with the earlier reports indicating the formation of ZnONPs [30]. The chemical structure of the ZnONPs capped by ME was studied using FTIR analysis, and the FTIR results of the ZnONPs and ME are shown in Figure 1c. The wideband at $3265 \mathrm{~cm}^{-1}$ was owing to the primary amine and $\mathrm{O}-\mathrm{H}$ stretching, while the peak detected at $2930 \mathrm{~cm}^{-1}$ was ascribed to the stretching vibration of the C-H groups [38]. The peak found at $1650 \mathrm{~cm}^{-1}$ was owing to the amide peak. Peaks at 1410 and $1035 \mathrm{~cm}^{-1}$ were accredited to the $\mathrm{O}-\mathrm{H}$ bending and stretching vibrations, respectively [39]. The stretching vibration of primary amines and $\mathrm{O}-\mathrm{H}$ is most likely associated with the 
bioactive components (proteins, flavonoids, phenolic acids, tannins, and carbohydrates) of the mushroom extract responsible for capping the ZnONPs [40]. The FTIR data established that the ZnONPs were efficaciously capped with several polyphenolic and biomolecules present in the mushroom extract. The observed results are also in line with the formerly available report [41].

(a)

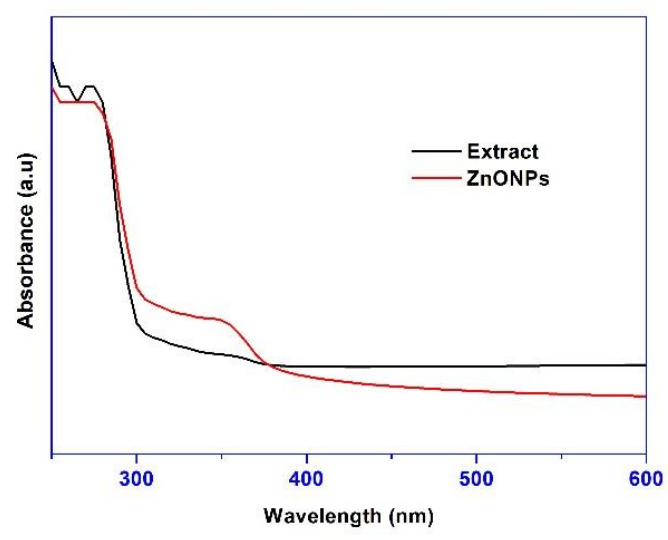

(b)



\section{(c)}



(d)

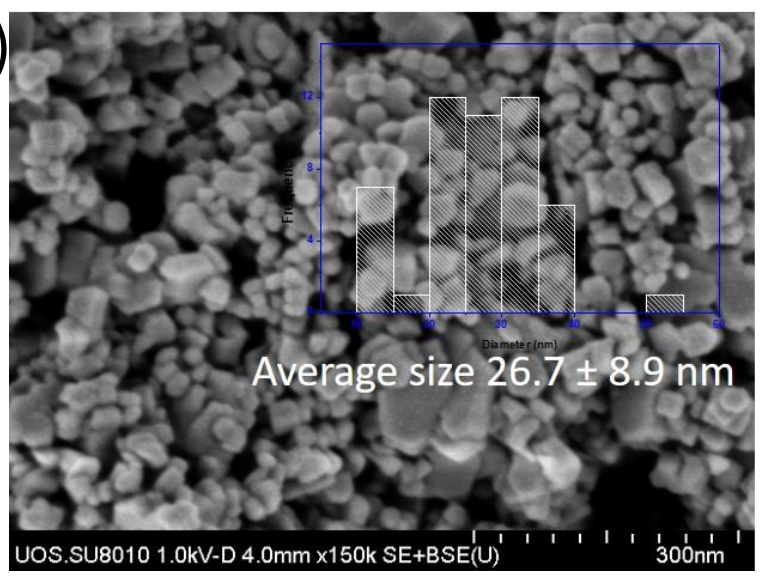

(e)

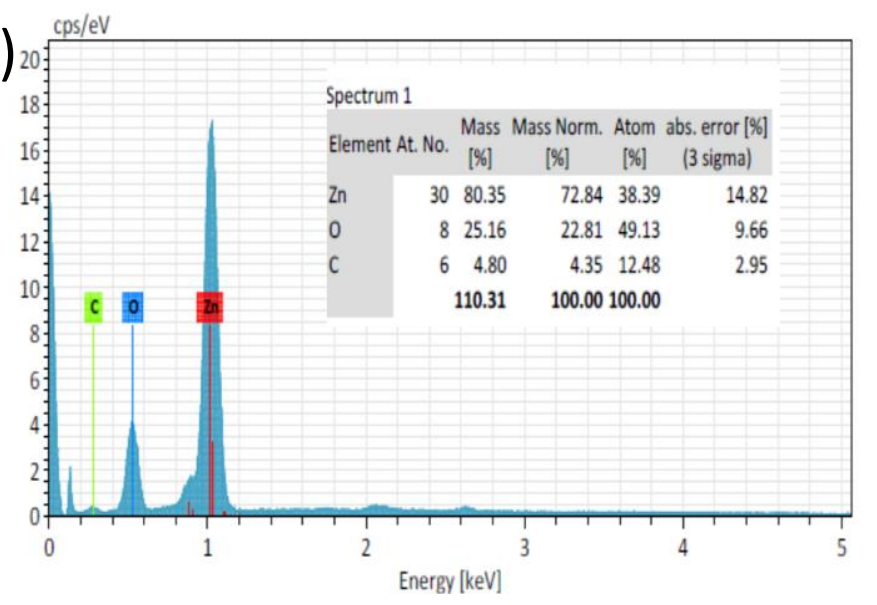

Figure 1. (a) UV-vis spectra, (b) XRD pattern, (c) FTIR spectra, and (d,e) FESEM and EDX of ZnONPs.

For further characterization of the ZnONPs, the hydrodynamic particle size $\left(Z_{\mathrm{avg}}\right)$ and polydispersity index (PDI) were analyzed using dynamic light scattering. The $\mathrm{Z}_{\mathrm{avg}}$ and PDI 
were $451.3 \pm 24.8 \mathrm{~nm}$ and $0.36 \pm 0.01$, respectively (Figure S1, Supporting Information), demonstrating the development of monodispersed nano-sized particles. The stability of the nanoparticles in an aqueous condition was checked by zeta potential, and the obtained data $(-25.2 \pm 0.5 \mathrm{mV}$, Figure S1, Supporting Information) revealed the moderate stability of the nanoparticles $[42,43]$. The stability of the ME-capped ZnONPs solution was very similar to the earlier reported melanin-mediated ZnONPs [30]. For the morphology of the particles, FESEM analysis was performed, and the results are presented in Figure 1d. The microscopic analysis showed irregular-shaped ZnONPs with a size of $\sim 10-40 \mathrm{~nm}$, with an average size of $26.7 \pm 8.9 \mathrm{~nm}$. The presence of elemental $\mathrm{Zn}$ and $\mathrm{O}$ was also further verified from the energy-dispersive X-ray spectroscopy (EDX) (Figure 1e). The elemental analysis was further confirmed by the XPS spectrum (Figure 2). The scan survey spectrum of ME-capped ZnONPs and C1s, N1s, O1s, and Zn2p are shown in Figure 2. The XPS spectra exhibited the binding energies of C1s, N1s, O1s, and Zn2p at about 284, 399, 530, and $1020 \mathrm{eV}$, respectively. Apart from the peaks of $\mathrm{Zn}$ and $\mathrm{O}$, supplementary peaks of $\mathrm{C}$ and $\mathrm{N}$ were detected, most likely owing to the capping of ME. The results of the binding energy values for Zn2p and O1s are consistent with formerly described data [44]. Thus, the resulting characterization established the formation of ME-capped nano-sized particles.
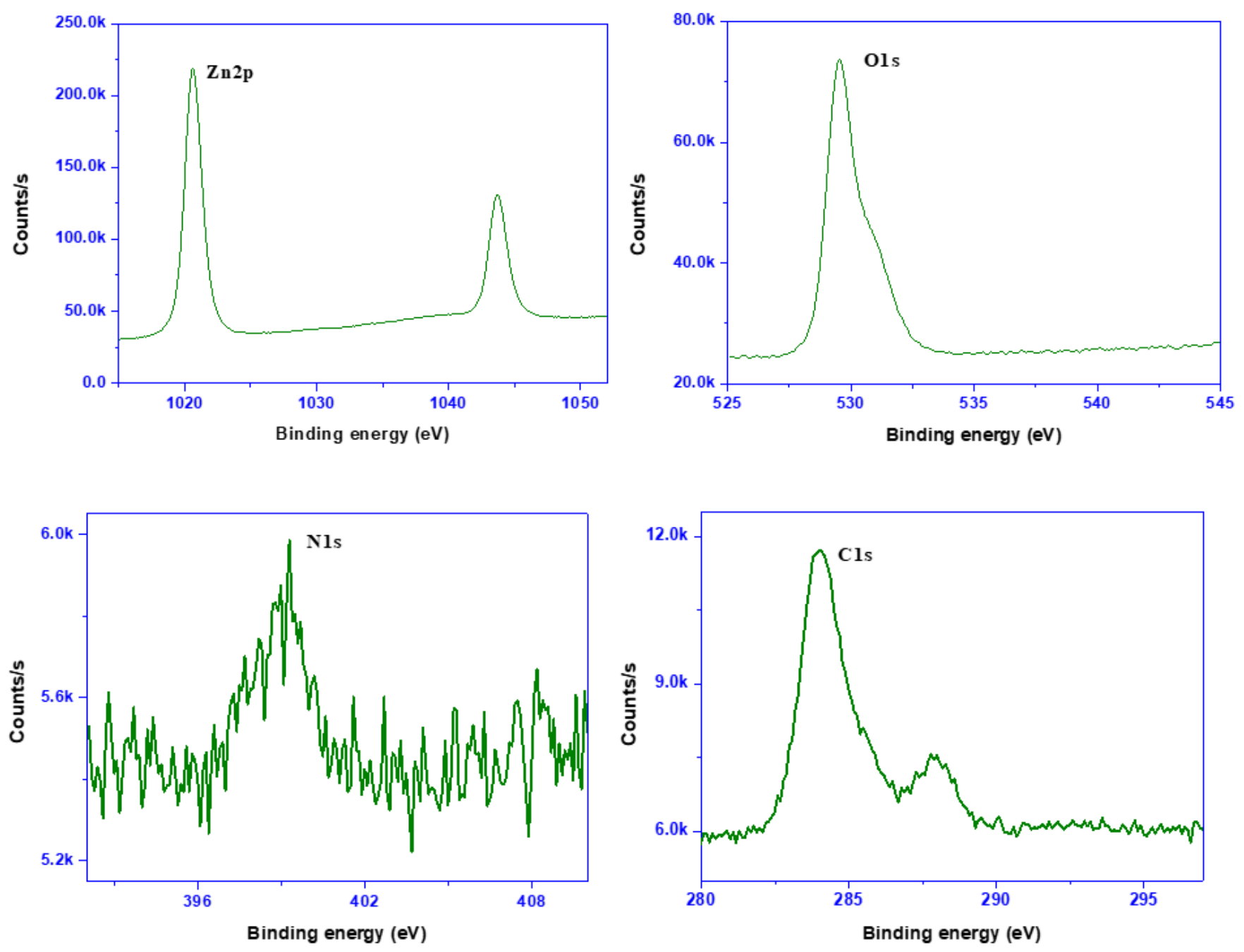

Figure 2. XPS spectra of ZnONPs. 


\subsection{Properties of the Pullulan/Chitosan-Based Composite Films}

\subsubsection{Apparent Color and Optical Properties}

The appearance and light transmittance spectra of pullulan/chitosan-based binary biocomposite films are presented in Figure 3. The neat pullulan/chitosan (PLN/CTS) film and the ZnONPs-added (PLN/CTS/ZnO) film were slightly yellowish and transparent, while the film with propolis was yellowish due to the color of propolis. The light transmittance spectra of the film showed that all the films were see-through to visible light. The control films also exhibited a peak at $280 \mathrm{~nm}$ owing to the UV-light absorption of chitosan. The reinforcement of the film with ZnONPs slightly reduced the UV light transmittance. Nevertheless, the addition of propolis pointedly condensed the UV transmittance of the pullulan/chitosan film. The combined use of ZnONPs and propolis showed a somewhat synergistic effect in the reduction of the UV-light transmittance of the film. The film's UV-light barrier and transparency were assessed, and the results are presented in Table 1. The neat film showed excellent transparency with more than $91 \%$ of the $\mathrm{T}_{660}$. The alloying of ZnONPs and propolis alone or in combination in pullulan/chitosan did not reflect any significant reduction of the transparency of the film. Nonetheless, the alloying of $\mathrm{ZnONPs}$ slightly reduced the UV-light transmittance $\left(\mathrm{T}_{280}\right)$, while the mixing of propolis showed a sharp decrease in UV-light transmittance ( $24.7 \%$ to $7.0 \%$ ) due to the polyphenolic compounds present in the propolis. The ZnONPs and propolis together somewhat synergistically decreased $\mathrm{T}_{280}$ to $6.4 \%$. Hence, it can be inferred that adding the fillers makes a highly transparent film and enhances its UV-light barrier properties.
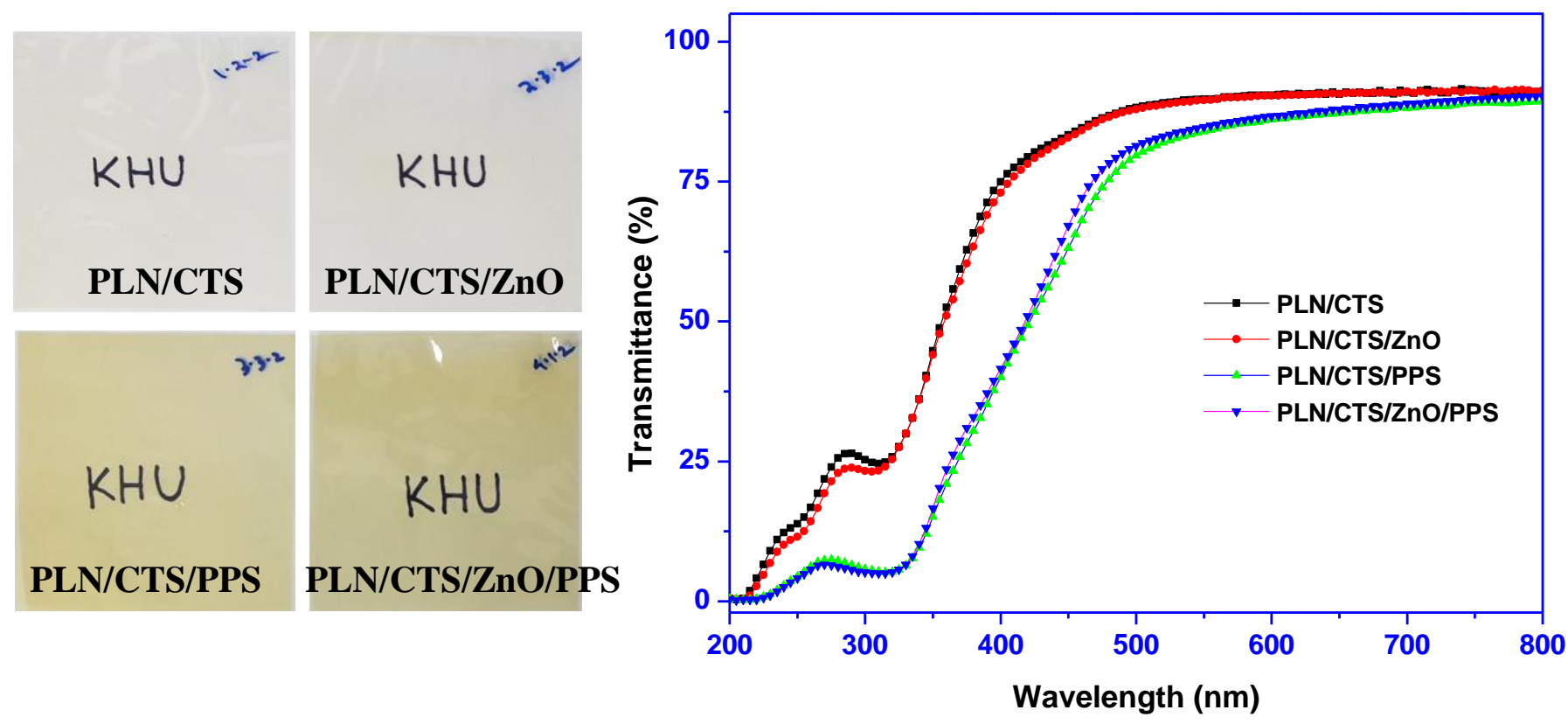

Figure 3. The appearance and transmittance spectra of the pullulan/chitosan-based composite films.

Table 1. Surface color and transmittance of pullulan/chitosan-based bioactive composite films.

\begin{tabular}{|c|c|c|c|c|c|c|c|c|}
\hline Films & $L$ & $a$ & $b$ & $\Delta E$ & WI & YI & $\mathrm{T}_{280}(\%)$ & $T_{660}(\%)$ \\
\hline PLN/CTS & $90.7 \pm 0.3^{c}$ & $-2.3 \pm 0.3^{c}$ & $13.5 \pm 1.4^{\mathrm{a}}$ & $9.2 \pm 1.5^{\mathrm{a}}$ & $86.0 \pm 1.4^{c}$ & $21.2 \pm 2.3^{\mathrm{a}}$ & $24.7 \pm 1.9^{c}$ & $91.2 \pm 0.3^{c}$ \\
\hline $\mathrm{PLN} / \mathrm{CTS} / \mathrm{ZnO}$ & $90.7 \pm 0.1^{c}$ & $-2.1 \pm 0.1^{c}$ & $12.2 \pm 0.5^{\mathrm{a}}$ & $7.9 \pm 0.5^{b}$ & $87.2 \pm 0.5^{c}$ & $19.2 \pm 0.8^{b}$ & $23.1 \pm 0.6^{c}$ & $90.6 \pm 0.3^{b}$ \\
\hline PLN/CTS/PPS & $88.1 \pm 0.3^{b}$ & $-5.1 \pm 0.2^{\mathrm{a}}$ & $25.8 \pm 1.1^{\mathrm{c}}$ & $22.0 \pm 1.1^{\mathrm{d}}$ & $73.5 \pm 1.1^{\mathrm{a}}$ & $41.8 \pm 1.8^{\mathrm{d}}$ & $7.0 \pm 0.4^{b}$ & $88.1 \pm 0.6^{a}$ \\
\hline PLN/CTS/ZnO/PPS & $87.0 \pm 0.3^{a}$ & $-4.0 \pm 0.2^{b}$ & $23.2 \pm 1.1^{\mathrm{b}}$ & $19.7 \pm 1.2^{c}$ & $76.1 \pm 1.1^{b}$ & $38.1 \pm 2.0^{c}$ & $6.4 \pm 0.4^{\mathrm{a}}$ & $88.6 \pm 0.5^{a}$ \\
\hline
\end{tabular}

The data are denoted as a mean \pm standard deviation. In the same column, any two means, followed by the same letter, are not meaningfully $(p>0.05)$ dissimilar from Duncan's multiple range test. 
The surface color data and related color parameters are shown in Table 1 . As anticipated from the UV-vis spectra, the lightness ( $L$-value) of all the films was over $87 \%$, indicating that the lightness was not considerably altered due to the reinforcement with fillers. The $a$-value was also not much transformed, although the $b$-value was amplified in the case of propolis, demonstrating increased yellowness. Accordingly, the total color difference $(\Delta E)$ of the films also increased significantly $(p<0.05)$ when reinforced with propolis, even if adding ZnONPs alone had shown a reduction in $\Delta E$. The whiteness index (WI) showed a slight increase in the presence of ZnONPs but showed a decreasing trend in the presence of propolis, which is presumably due to the yellowness of propolis. As expected, the yellowness index (YI) of the film was significantly increased by the addition of propolis.

\subsubsection{Morphology}

The morphological structure of the film was observed using the FE-SEM (surface and cross-section) and AFM, and the data are shown in Figure 4. The SEM surface images showed all films were smooth surfaced, without any outward defects. By alloying, pullulan and chitosan produce a compatible film [22]. The reinforcement with ZnONPs or propolis did not meaningly transform the morphology of the film, indicating their appropriate miscibility in the binary polymer matrices. The cross-section morphology low and high magnification also showed a proper distribution of fillers in the polymers without significantly altering the morphology of the control films. Interestingly, incorporating ZnONPs did not induce any agglomerated particles, suggesting the proper blending of nanofillers in the polymer matrices could contribute to the good adhesion of the filler and the pullulan/chitosan matrix. For more insight into the nanofillers' distribution, elemental mapping was carried out (Figure S2, Supporting Information), and the results showed a uniform distribution of the nanoparticles in the polymer matrices. Moreover, the morphology of the films was checked by AFM micrographs (Figure 4), and the results showed a good dispersion of the fillers analogous to the SEM data. The surface roughness of the film was also determined from the AFM micrographs, and the obtained $\mathrm{Ra}$ and $\mathrm{Rq}$ values (data not shown) indicate that the increase in roughness was observed only for ZnONPs while adding propolis did not significantly alter the roughness of the pullulan/chitosan films.

\subsubsection{Mechanical Properties}

The mechanical properties of the pullulan/chitosan-based films were determined in terms of the tensile strength (TS), elongation at break (EB), and elastic modulus (EM), and the results are shown in Table 2. The thickness of the control blend film was $43.1 \mu \mathrm{m}$, which slightly decreased to $41.6 \mu \mathrm{m}$ with the mixing of ZnONPs. This might be due to the formation of H-bonding between ZnONPs and chitosan, which may have pulled the polymer chains closer, resulting in enhanced compactness and decreased thickness [45]. However, when propolis was added to the neat blend films, the thickness increased to $47 \mu \mathrm{m}$. The reason for this may be the high molecular weight of polyphenols in propolis, which occupy the interchain spaces in the polymer matrix, pushing them farther apart [46,47]. Also, this phenomenon designates the absence of any chemical interaction among propolis and the polymer chains. When both ZnONPs and propolis were added, the effect of both the additives balanced each other, resulting in a thickness of $45.5 \mu \mathrm{m}$. Nevertheless, the variation in the thickness among different films was not statistically significant.

The TS values confirm the H-bonding interaction of the ZnONPs with the biopolymer chains. The TS of the PLN/CTS/ZnO and PLN/CTS/ZnO/PPS films were $61.5 \mathrm{MPa}$ and 62.6 MPa, respectively, indicating statistically significant $\sim 24 \%$ and $\sim 26 \%$ increments compared to neat PLN/CTS blends. However, the PLN/CTS/PPS film showed an insignificant increase (by 4\%) in the TS value. Likewise, the EM values of the the ZnONPs-incorporated films also increased to 2.6 GPa compared to 2.2 GPa for films without ZnONPs. Additionally, the EB values were decreased more for the ZnONPs-incorporated films. Nevertheless, 
the difference in the EM and EB values was not statistically significant, indicating minor variations in the flexibility and stiffness of the films [48].
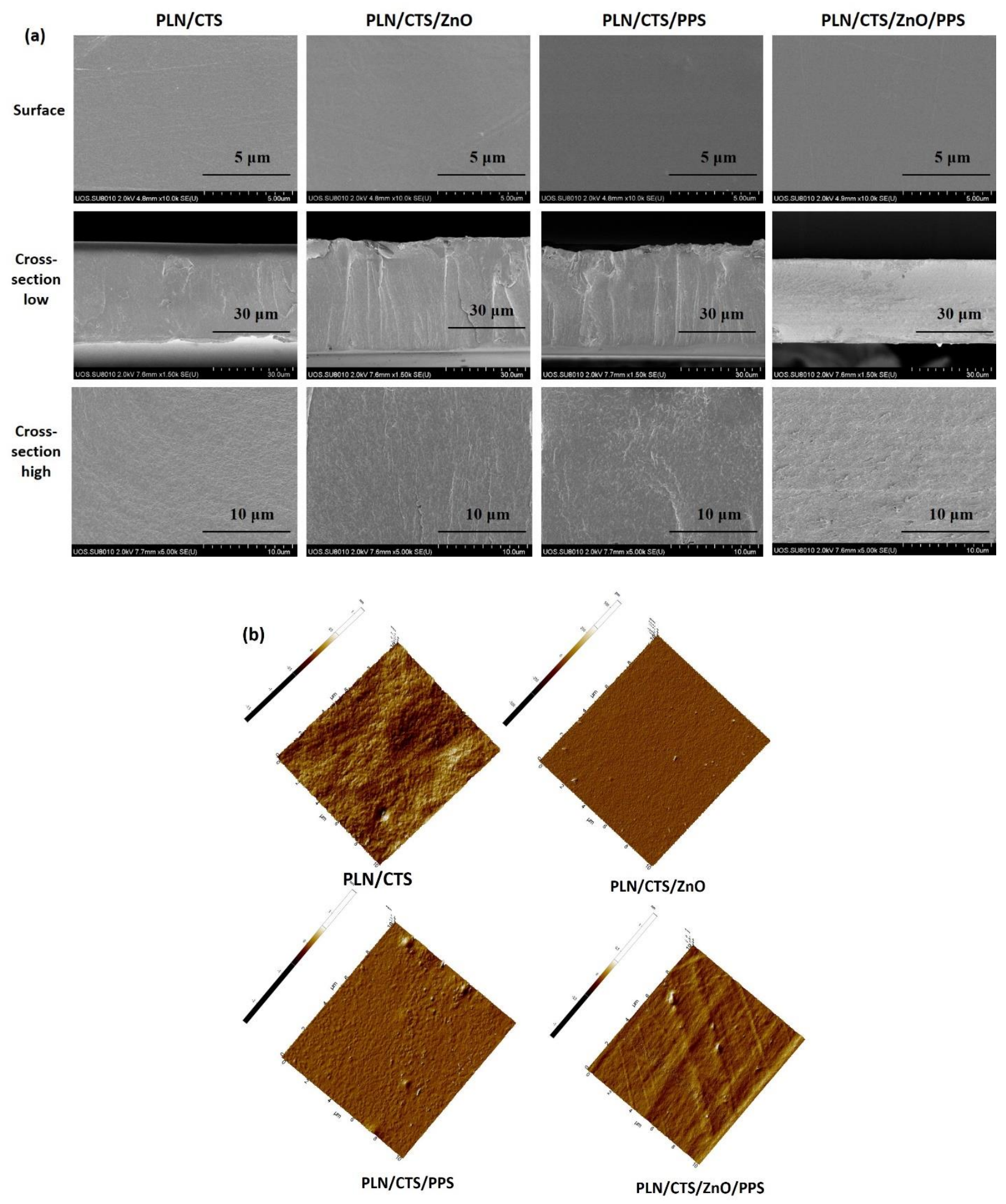

Figure 4. FESEM surface and cross-section micrographs (a) and AFM images (b) of pullulan/chitosan-based composite films. 
Table 2. Mechanical properties, water vapor permeability, and water contact angle of pullulan/chitosan-based bioactive films.

\begin{tabular}{|c|c|c|c|c|c|c|}
\hline Films & Thickness $(\mu \mathrm{m})$ & TS (MPa) & EB (\%) & EM (GPa) & $\begin{array}{l}\text { WVP }\left(\times 10^{-9}\right. \\
\left.\text { g.m } / \mathrm{m}^{2} . \text { Pa.s }\right)\end{array}$ & WCA (deg.) \\
\hline PLN/CTS & $43.1 \pm 5.0^{\mathrm{a}}$ & $49.7 \pm 5.3^{\mathrm{a}}$ & $5.9 \pm 1.0^{b}$ & $2.2 \pm 0.2^{a}$ & $0.77 \pm 0.01^{b}$ & $56.5 \pm 3.8^{a}$ \\
\hline PLN/CTS/ZnO & $41.6 \pm 3.9^{a}$ & $61.5 \pm 4.3^{c}$ & $4.8 \pm 0.9^{a}$ & $2.6 \pm 0.3^{b}$ & $0.79 \pm 0.03^{b}$ & $59.6 \pm 1.6^{\mathrm{ab}}$ \\
\hline PLN/CTS/PPS & $47.0 \pm 5.2^{a}$ & $51.7 \pm 4.8^{b}$ & $5.7 \pm 0.5^{b}$ & $2.2 \pm 0.2^{a}$ & $0.72 \pm 0.04^{\mathrm{a}}$ & $64.6 \pm 4.1^{\mathrm{c}}$ \\
\hline PLN/CTS/ZnO/PPS & $45.5 \pm 4.5^{\mathrm{a}}$ & $62.6 \pm 4.2^{\mathrm{c}}$ & $5.2 \pm 0.4^{\mathrm{ab}}$ & $2.6 \pm 0.2^{b}$ & $0.69 \pm 0.01^{\mathrm{a}}$ & $61.3 \pm 2.0^{b}$ \\
\hline
\end{tabular}

The data are denoted as a mean \pm standard deviation. In the same column, any two means, followed by the same letter, are not meaningfully $(p>0.05)$ dissimilar from Duncan's multiple range tests.

\subsubsection{Water Vapor Permeability (WVP) and Water Contact Angle (WCA)}

The changes in the WVP and WCA values upon incorporating ZnONPs and propolis are shown in Table 2. No statistically meaningful change in the WVP value was observed due to incorporating ZnONPs in the blend films. Although it is reported that nanoparticles, when added to the polymer matrix, generally enhance the water vapor barrier properties by occupying the vacant interchain spaces and creating a tortuous path for the water molecules to pass through [45], some reports also indicate the opposite effect due to the hydrophilicity of the $\mathrm{ZnO}$ nanoparticles capped with biomolecules [49]. The unperturbed WVP values may be the result of the balance between both these attributes of ZnONPs. Conversely, adding propolis enhanced the water vapor barrier properties, which is attributed to the decreased hygroscopicity of the films resulting from the increased content of hydrophobic components in the propolis [50]. The WCA values displayed a similar trend where the films with propolis displayed high hydrophobicity compared to the neat blend films. However, the ZnONPs-incorporated films displayed increased interaction with water due to their hydrophilic nature. Despite this, all the films displayed substantial increments in the WCA values. However, the films could not be classified as hydrophobic as the WCA values were not above $65^{\circ}$, which is the recommended WCA value for hydrophobic films [51]. Nevertheless, the PLN/CTS/PPS films exhibited a WCA value of $64.6^{\circ}$, making them the most hydrophobic of their counterparts.

\subsubsection{FTIR and Thermal Analysis}

The results of the structural characterization of the films and their thermal analysis are provided in the Supplementary Information, Figures S3 and S4, respectively.

\subsection{Antimicrobial Activity}

The antimicrobial activity of the pullulan/chitosan-based films was studied against Gram-positive L. monocytogenes and Gram-negative E. coli bacteria, and the results are presented in Figure 5. The neat PLN/CTS film displayed significant antimicrobial activity toward the tested bacteria due to chitosan's antimicrobial action [52]. For both the bacterial strains, the growth after $12 \mathrm{~h}$ reached $>9 \mathrm{Log} \mathrm{CFU} / \mathrm{mL}$ for the control group. However, for the groups exposed to the PLN/CTS films, the growth after $12 \mathrm{~h}$ was reduced to $\sim 3 \mathrm{Log}$ $\mathrm{CFU} / \mathrm{mL}$ against both the bacteria, indicating the strong antimicrobial activity of chitosan. With the addition of propolis, no remarkable difference in the bactericidal action was observed against either bacteria, signifying no antimicrobial activity of the polyphenolic extract. Similar results were obtained previously [34]. However, as expected, the antimicrobial action of the films was boosted with the blending of ZnONPs. Against E. coli, a 100\% bactericidal effect was observed for the PLN/CTS/ZnO film after $9 \mathrm{~h}$. Interestingly, the $\mathrm{PLN} / \mathrm{CTS} / \mathrm{ZnO} / \mathrm{PPS}$ film exerted the same effect at a $6 \mathrm{~h}$ interval, indicating the possible synergistic bactericidal effect of $\mathrm{ZnONPs}$ and propolis. However, this effect was not observed against $L$. monocytogenes, and $100 \%$ bacterial inhibition was observed after $12 \mathrm{~h}$ for the PLN/CTS/ZnO and PLN/CTS/ZnO/PPS films. The results also indicated a higher 
antimicrobial activity of ZnONPs toward Gram-negative bacteria than Gram-positive ones, which is consistent with previous reports [26,28].
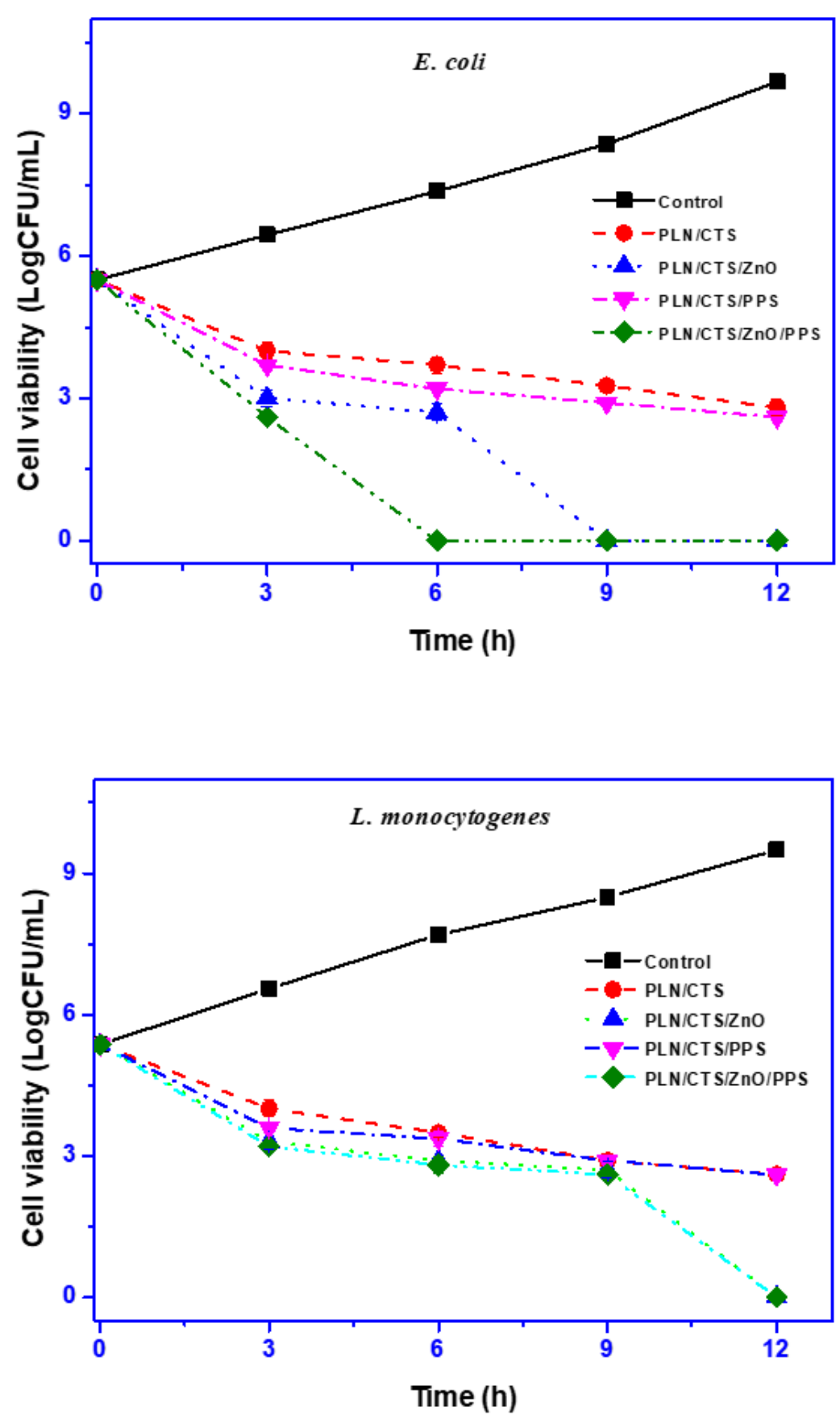

Figure 5. Antimicrobial activity of pullulan/chitosan-based composite films.

\subsection{Antioxidant Activity}

Figure 6 shows the outcomes of the antioxidant activity of the pullulan/chitosan-based films studied against DPPH and ABTS free radicals. The PLN/CTS film showed $\sim 5 \%$ and $\sim 33 \%$ antioxidant activity toward DPPH and ABTS free radicals, respectively, due to the presence of chitosan. The antioxidant activity of chitosan has been reported previously and is attributed to the protonated amine group, which stabilizes the free radicals [53]. Additionally, the higher activity against ABTS compared to DPPH occurredbecause hydrophilic chitosan interacts better with ABTS, due to its aqueous solution, than with the methanolic DPPH solution [51]. With the addition of ZnONPs, no variation in the antioxidant activity 
was detected. However, when propolis was mixed with the pullulan/chitosan films, the antioxidant activity sharply increased to $\sim 30 \%$ and $\sim 70 \%$ against DPPH and ABTS, respectively. This signifies that propolis imparts a strong antioxidant property to the films due to its polyphenolic composition [34,54]. Previous studies also report the enhanced antioxidant action of bio-based polymer films upon the addition of propolis [34]. Interestingly, for the PLN/CTS/ZnO/PPS film, the antioxidant activity was slightly decreased compared to the PLN/CTS/PPS films. This may be owing to the capability of ZnONPs to bring out reactive oxygen species, including oxidative free radicals, which counter the effect of propolis. This observation was previously reported as well [28].

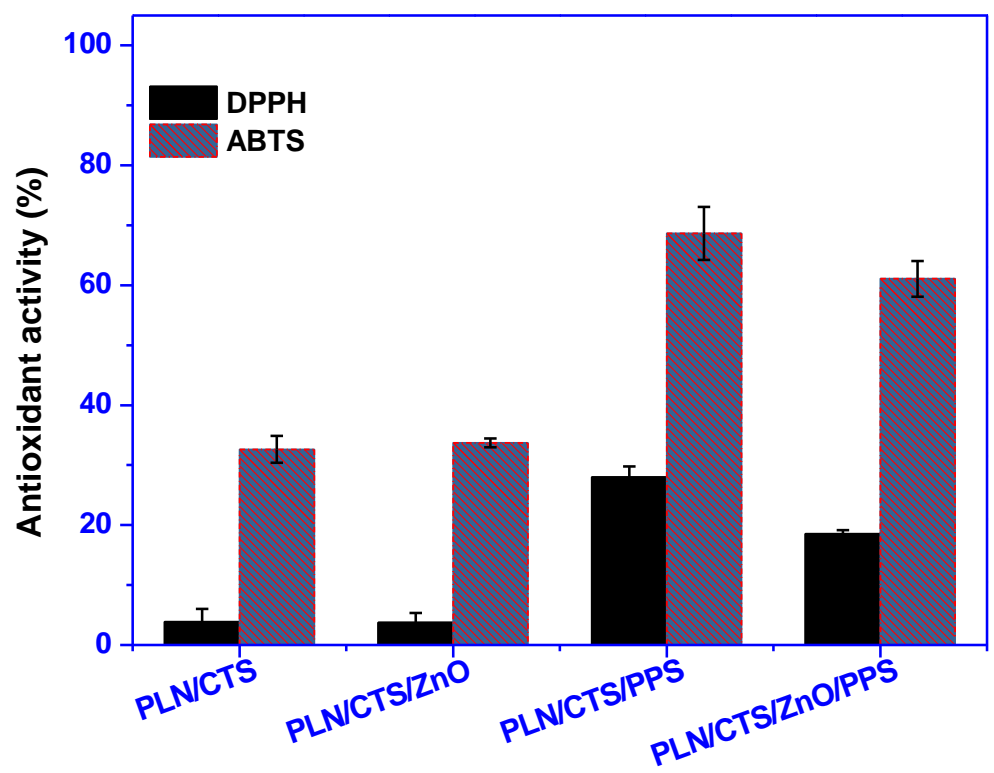

Figure 6. Antioxidant activity of pullulan/chitosan-based composite films.

\subsection{Meat Packaging Test}

The commonly used preservation method for meat products is refrigeration after skintight packaging using PE/PP films. However, certain bacteria can grow and contaminate the packed meat even under these conditions [55]. Hence, estimating the total aerobic bacterial count (TABC) on the packed meat offers critical evidence about its hygiene and safety. The total aerobic bacterial count of the pork loin meat stored at $10^{\circ} \mathrm{C}$ was estimated for 8 days, and the results are presented in Figure 7a. The initial TABC on the packed pork loin meat sample was $<2 \mathrm{Log}$ CFU/g. A rapid increase in the TABC was observed for the control samples while storage reached $\sim 6 \mathrm{Log}$ CFU $/ g$ after 6 days and finally $\sim 9 \mathrm{Log}$ CFU $/ \mathrm{g}$ within 8 days. As per the International Commission on Microbiological Specifications for Foods (ICMSF) regulations, an upper acceptable microbiological limit of 7 Log CFU/g has been proposed for meat products [55-57]. According to this proposed limit, the packed meat in the control group was deemed consumable for up to 6 days. However, for the meat samples wrapped with the PLN/CTS/ZnO/PPS film before packaging, the TABC value remained at $6.7 \mathrm{Log} \mathrm{CFU} / \mathrm{g}$ even after 8 days of storage, below the proposed upper acceptable microbiological limit. Additionally, this value was significantly $(p>0.05)$ lower than that obtained for the control group. Several researchers performed studies on various meat types and determined them to be consumable if the TABC value remained below $7 \mathrm{Log}$ CFU/g [28,55,58,59]. Hence, it can be inferred that the PLN/CTS/ZnO/PPS film can act as an extra wrapping material that may expand the shelf life of packed pork meat, acting in the form of hurdle technology. 
(a)

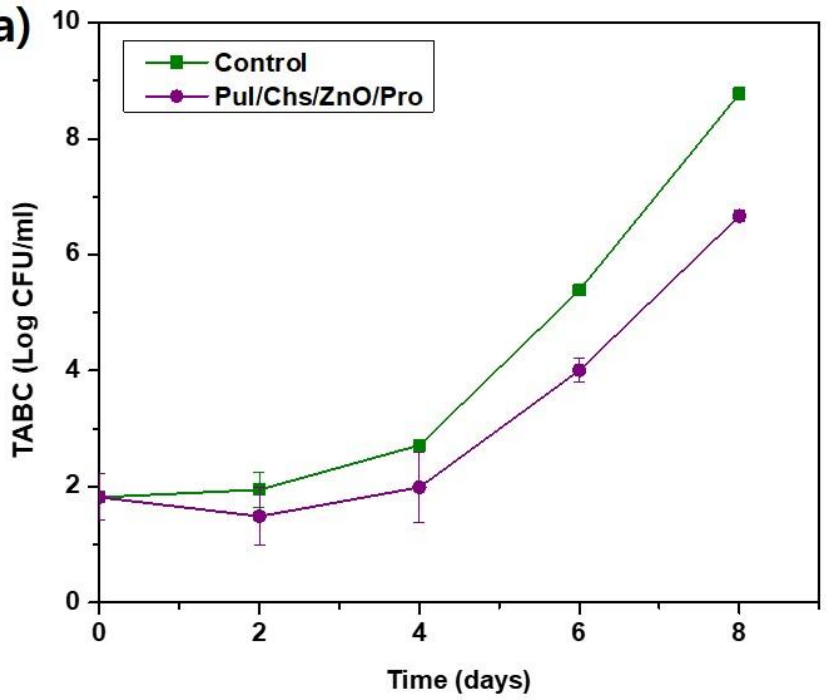

(b)

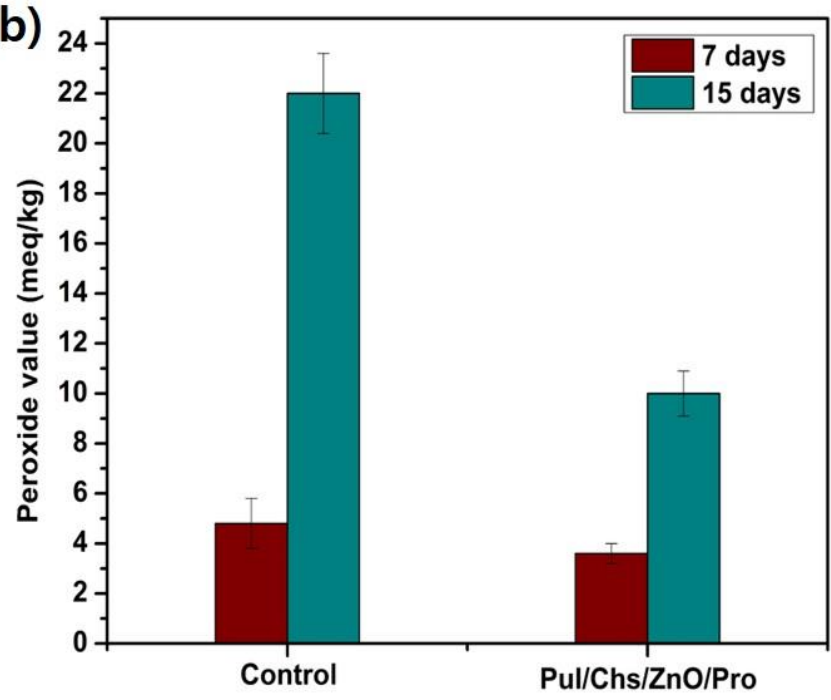

Figure 7. Application of pullulan/chitosan-based composite films for packaging of pork belly meat. (a) Total aerobic bacterial count, (b) peroxide values stored at $10{ }^{\circ} \mathrm{C}$.

Besides microbial contamination, the lipid oxidation in the packed meat product is another important factor determining its quality and shelf life. The oxidation of meat lipids is inevitable during storage and transportation and renders the product rancid over time, making it unpalatable [55]. Hydroperoxides are the principal lipid peroxidation compounds that cause the development of off-flavors in food [28]. Hence, their assessment provides important evidence about the packed food quality. The peroxide values (PV) of the packed pork loin meat were determined over time, and the results are reported in Figure $7 \mathrm{~b}$. The initial value of lipid peroxidation in the packed meat was $0 \mathrm{meq} / \mathrm{kg}$, which amplified over time, depending on the package type. After 7 days of storage, the control and test samples exhibited peroxide values of $\sim 5 \mathrm{meq} / \mathrm{kg}$ and $\sim 4 \mathrm{meq} / \mathrm{kg}$, respectively, which were not considerably different statistically $(p<0.05)$. However, after 15 days of storing, while the PV of the meat packed in the control group increased abruptly to $22 \mathrm{meq} / \mathrm{kg}$, the meat wrapped in the PLN/CTS/ZnO/PPS film exhibited a far lower peroxide value of $\sim 10 \mathrm{meq} / \mathrm{kg}$, showing around $55 \%$ decreased lipid oxidation, indicating a statistically significant $(p>0.05)$ reduction. This result was consistent with the antioxidant test results for the films (Figure 6), which indicate their oxidative free radical scavenging ability.

\section{Conclusions}

The main aim of this work was to investigate the effects of green-synthesized ZnONPs and propolis on the properties (physical and functional) of the pullulan/chitosan-based film for meat packaging applications. The ZnONPs were developed using enoki mushroom extract, and the obtained nanoparticles were stable and in a size range of $10-40 \mathrm{~nm}$. Adding ZnONPs and propolis significantly enhanced the UV-light blocking and mechanical properties without significantly changing thermal stability. The alloying of fillers also slightly enhanced the water vapor barrier properties and hydrophobicity compared to the neat films. Additionally, the pullulan/chitosan-based binary composite film presented strong antibacterial activity toward E. coli and L. monocytogenes and showed excellent antioxidant activity. The PLN/CTS/ZnO/PPS film was used to wrap pork loin meat, and the TABC and PV data clearly showed that the growth of bacteria and lipid peroxidation was hindered in the packaged meat. 
Supplementary Materials: The following are available online at https:/ / www.mdpi.com/article/10 .3390/foods10112789/s1: Experiment, results, and discussion, Figure S1; DLS analysis (size and Zeta potential) of ZnONPs, Figure S2; Elemental mapping of PLN/CTS/ZnO/PPS film, Figure S3; FTIR spectra of pullulan/chitosan-based bioactive composite films, Figure S4; TGA and DTG thermograms of pullulan/chitosan-based bioactive composite films, References.

Author Contributions: Data curation, S.R. and R.P.; investigation, S.R. and R.P.; software, S.R.; visualization, S.R. and R.P.; writing—original draft, S.R. and R.P.; writing—review \& editing, J.-W.R. All authors have read and agreed to the published version of the manuscript.

Funding: This work was supported by the National Research Foundation of Korea (NRF) grant funded by the Korean government (MSIT) (No. 2019R1A2C2084221) and the Brain Pool Program funded by the Ministry of Science, ICT, and Future Planning through the NRF (2019H1D3A1A01070715).

Institutional Review Board Statement: Not Applicable.

Informed Consent Statement: Not Applicable.

Data Availability Statement: The data presented in this study are available on request from the corresponding author.

Conflicts of Interest: The authors declare no conflict of interest.

\section{References}

1. Karwowska, M.; Łaba, S.; Szczepański, K. Food Loss and Waste in Meat Sector-Why the Consumption Stage Generates the Most Losses? Sustainability 2021, 13, 6227. [CrossRef]

2. Fang, Z.; Zhao, Y.; Warner, R.D.; Johnson, S. Active and intelligent packaging in meat industry. Trends Food Sci. Technol. 2017, 61, 60-71. [CrossRef]

3. Barone, A.S.; Matheus, J.R.V.; de Souza, T.S.P.; Moreira, R.F.A.; Fai, A.E.C. Green-based active packaging: Opportunities beyond COVID-19, food applications, and perspectives in circular economy-A brief review. Compr. Rev. Food Sci. Food Saf. 2021, 20, 4881-4905. [CrossRef] [PubMed]

4. Qian, M.; Liu, D.; Zhang, X.; Yin, Z.; Ismail, B.B.; Ye, X.; Guo, M. A review of active packaging in bakery products: Applications and future trends. Trends Food Sci. Technol. 2021, 114, 459-471. [CrossRef]

5. Domínguez, R.; Barba, F.J.; Gómez, B.; Putnik, P.; Kovačević, D.B.; Pateiro, M.; Santos, E.M.; Lorenzo, J.M. Active packaging films with natural antioxidants to be used in meat industry: A review. Food Res. Int. 2018, 113, 93-101. [CrossRef] [PubMed]

6. Huang, J.; Hu, Z.; Hu, L.; Li, G.; Yao, Q.; Hu, Y. Pectin-based active packaging: A critical review on preparation, physical properties and novel application in food preservation. Trends Food Sci. Technol. 2021, 118, 167-178. [CrossRef]

7. Wicochea-Rodríguez, J.D.; Chalier, P.; Ruiz, T.; Gastaldi, E. Active Food Packaging Based on Biopolymers and Aroma Compounds: How to Design and Control the Release. Front. Chem. 2019, 7, 398. [CrossRef]

8. Jamróz, E.; Kopel, P. Polysaccharide and Protein Films with Antimicrobial/Antioxidant Activity in the Food Industry: A Re-view. Polymers 2020, 12, 1289. [CrossRef]

9. Sivakanthan, S.; Rajendran, S.; Gamage, A.; Madhujith, T.; Mani, S. Antioxidant and antimicrobial applications of biopolymers: A review. Food Res. Int. 2020, 136, 109327. [CrossRef]

10. Adeyeye, O.A.; Sadiku, E.R.; Reddy, A.B.; Ndamase, A.S.; Makgatho, G.; Sellamuthu, P.S.; Perumal, A.B.; Nambiar, R.B.; Fasiku, V.O.; Ibrahim, I.D.; et al. The Use of Biopolymers in Food Packaging. In Green Biopolymers and Their Nanocomposites; Springer: Singapore, 2019; pp. 137-158.

11. Roy, S.; Rhim, J.-W. Anthocyanin food colorant and its application in $\mathrm{pH}$-responsive color change indicator films. Crit. Rev. Food Sci. Nutr. 2021, 61, 2297-2325. [CrossRef]

12. Roy, S.; Rhim, J.-W. New insight into melanin for food packaging and biotechnology applications. Crit. Rev. Food Sci. Nutr. 2021, 1-27. [CrossRef] [PubMed]

13. Gnanasekaran, D. Green Biopolymers and Its Nanocomposites in Various Applications: State of the Art; Springer Science and Business Media LLC: Singapore, 2019; pp. 1-27.

14. Sady, S.; Błaszczyk, A.; Kozak, W.; Boryło, P.; Szindler, M. Quality assessment of innovative chitosan-based biopolymers for edible food packaging applications. Food Packag. Shelf Life 2021, 30, 100756. [CrossRef]

15. Roy, S.; Rhim, J.-W. Fabrication of bioactive binary composite film based on gelatin/chitosan incorporated with cinnamon essential oil and rutin. Colloids Surf. B Biointerfaces 2021, 204, 111830. [CrossRef]

16. Rukmanikrishnan, B.; Ramalingam, S.; Rajasekharan, S.K.; Lee, J.; Lee, J. Binary and ternary sustainable composites of gellan gum, hydroxyethyl cellulose and lignin for food packaging applications: Biocompatibility, antioxidant activity, UV and water barrier properties. Int. J. Biol. Macromol. 2020, 153, 55-62. [CrossRef]

17. Priyadarshi, R.; Kim, S.-M.; Rhim, J.-W. Pectin/pullulan blend films for food packaging: Effect of blending ratio. Food Chem. 2021, 347, 129022. [CrossRef] [PubMed] 
18. Roy, S.; Kim, H.-J.; Rhim, J.-W. Effect of blended colorants of anthocyanin and shikonin on carboxymethyl cellulose/agar-based smart packaging film. Int. J. Biol. Macromol. 2021, 183, 305-315. [CrossRef] [PubMed]

19. Roy, S.; Rhim, J.-W. Fabrication of pectin/agar blended functional film: Effect of reinforcement of melanin nanoparticles and grapefruit seed extract. Food Hydrocoll. 2021, 118, 106823. [CrossRef]

20. Wu, J.; Zhong, F.; Li, Y.; Shoemaker, C.; Xia, W. Preparation and characterization of pullulan-chitosan and pullulan-carboxymethyl chitosan blended films. Food Hydrocoll. 2013, 30, 82-91. [CrossRef]

21. Li, Y.; Yokoyama, W.; Wu, J.; Ma, J.; Zhong, F. Properties of edible films based on pullulan-chitosan blended film-forming solutions at different pH. RSC Adv. 2015, 5, 105844-105850. [CrossRef]

22. Roy, S.; Rhim, J.-W. Effect of chitosan modified halloysite on the physical and functional properties of pullulan/chitosan biofilm integrated with rutin. Appl. Clay Sci. 2021, 211, 106205. [CrossRef]

23. Duan, M.; Yu, S.; Sun, J.; Jiang, H.; Zhao, J.; Tong, C.; Hu, Y.; Pang, J.; Wu, C. Development and characterization of electrospun nanofibers based on pullulan/chitin nanofibers containing curcumin and anthocyanins for active-intelligent food packaging. Int. J. Biol. Macromol. 2021, 187, 332-340. [CrossRef]

24. Li, S.; Yi, J.; Yu, X.; Wang, Z.; Wang, L. Preparation and characterization of pullulan derivative/chitosan composite film for potential antimicrobial applications. Int. J. Biol. Macromol. 2020, 148, 258-264. [CrossRef]

25. Kim, I.; Viswanathan, K.; Kasi, G.; Thanakkasaranee, S.; Sadeghi, K.; Seo, J. ZnO Nanostructures in Active Antibacterial Food Packaging: Preparation Methods, Antimicrobial Mechanisms, Safety Issues, Future Prospects, and Challenges. Food Rev. Int. 2020, 1-29. [CrossRef]

26. Roy, S.; Kim, H.; Panicker, P.; Rhim, J.-W.; Kim, J. Cellulose Nanofiber-Based Nanocomposite Films Reinforced with Zinc Oxide Nanorods and Grapefruit Seed Extract. Nanomaterials 2021, 11, 877. [CrossRef]

27. Roy, S.; Rhim, J.-W. Carboxymethyl cellulose-based antioxidant and antimicrobial active packaging film incorporated with curcumin and zinc oxide. Int. J. Biol. Macromol. 2020, 148, 666-676. [CrossRef]

28. Priyadarshi, R.; Kim, S.-M.; Rhim, J.-W. Carboxymethyl cellulose-based multifunctional film combined with zinc oxide nanoparticles and grape seed extract for the preservation of high-fat meat products. Sustain. Mater. Technol. 2021, 29, e00325. [CrossRef]

29. Xie, Y.; Pan, Y.; Cai, P. Cellulose-based antimicrobial films incroporated with ZnO nanopillars on surface as biodegradable and antimicrobial packaging. Food Chem. 2022, 368, 130784. [CrossRef]

30. Roy, S.; Rhim, J.-W. Carrageenan-based antimicrobial bionanocomposite films incorporated with ZnO nanoparticles stabilized by melanin. Food Hydrocoll. 2019, 90, 500-507. [CrossRef]

31. Arfat, Y.A.; Benjakul, S.; Vongkamjan, K.; Sumpavapol, P.; Yarnpakdee, S. Shelf-life extension of refrigerated sea bass slices wrapped with fish protein isolate/fish skin gelatin-ZnO nanocomposite film incorporated with basil leaf essential oil. J. Food Sci. Technol. 2015, 52, 6182-6193. [CrossRef]

32. Woźniak, M.; Mrówczyńska, L.; Waśkiewicz, A.; Rogoziński, T.; Ratajczak, I. Phenolic Profile and Antioxidant Activity of Propolis Extracts from Poland. Nat. Prod. Commun. 2019, 14, 1-7. [CrossRef]

33. Suriyatem, R.; Auras, R.A.; Rachtanapun, C.; Rachtanapun, P. Biodegradable Rice Starch/Carboxymethyl Chitosan Films with Added Propolis Extract for Potential Use as Active Food Packaging. Polymers 2018, 10, 954. [CrossRef]

34. Roy, S.; Rhim, J.-W. Preparation of Gelatin/Carrageenan-Based Color-Indicator Film Integrated with Shikonin and Propolis for Smart Food Packaging Applications. ACS Appl. Bio Mater. 2020, 4, 770-779. [CrossRef]

35. Galeotti, F.; Maccari, F.; Fachini, A.; Volpi, N. Chemical Composition and Antioxidant Activity of Propolis Prepared in Different Forms and in Different Solvents Useful for Finished Products. Foods 2018, 7, 41. [CrossRef]

36. Rabeea, M.A.; Owaid, M.N.; Aziz, A.A.; Jameel, M.S.; Dheyab, M.A. Mycosynthesis of gold nanoparticles using the extract of Flammulina velutipes, Physalacriaceae, and their efficacy for decolorization of methylene blue. J. Environ. Chem. Eng. 2020, 8, 103841. [CrossRef]

37. Roy, S.; Ezati, P.; Rhim, J.-W. Gelatin/Carrageenan-Based Functional Films with Carbon Dots from Enoki Mushroom for Active Food Packaging Applications. ACS Appl. Polym. Mater. 2021. [CrossRef]

38. Dai, L.; Zhang, J.; Cheng, F. Effects of starches from different botanical sources and modification methods on physicochemical properties of starch-based edible films. Int. J. Biol. Macromol. 2019, 132, 897-905. [CrossRef]

39. Ren, L.; Yan, X.; Zhou, J.; Tong, J.; Su, X. Influence of chitosan concentration on mechanical and barrier properties of corn starch/chitosan films. Int. J. Biol. Macromol. 2017, 105, 1636-1643. [CrossRef]

40. Philip, D. Biosynthesis of Au, Ag and Au-Ag nanoparticles using edible mushroom extract. Spectrochim. Acta Part A Mol. Biomol. Spectrosc. 2009, 73, 374-381. [CrossRef]

41. Faisal, S.; Khan, M.A.; Jan, H.; Shah, S.A.; Abdullah, A.; Shah, S.; Rizwan, M.; Ullah, W.; Akbar, M.T.; Redaina, R. Edible mushroom (Flammulina velutipes) as biosource for silver nanoparticles: From synthesis to diverse biomedical and environmental applications. Nanotechnology 2021, 32, 065101. [CrossRef] [PubMed]

42. Roy, S.; Das, T.K.; Maiti, G.P.; Basu, U. Microbial biosynthesis of nontoxic gold nanoparticles. Mater. Sci. Eng. B 2016, $203,41-51$. [CrossRef]

43. Ghosh, S.; Roy, S.; Naskar, J.; Kole, R.K. Process optimization for biosynthesis of mono and bimetallic alloy nanoparticle catalysts for degradation of dyes in individual and ternary mixture. Sci. Rep. 2020, 10,1-14. [CrossRef]

44. Al-Gaashani, R.; Radiman, S.; Daud, A.; Tabet, N.; Al-Douri, Y. XPS and optical studies of different morphologies of ZnO nanostructures prepared by microwave methods. Ceram. Int. 2013, 39, 2283-2292. [CrossRef] 
45. Priyadarshi, R.; Negi, Y.S. Effect of Varying Filler Concentration on Zinc Oxide Nanoparticle Embedded Chitosan Films as Potential Food Packaging Material. J. Polym. Environ. 2016, 25, 1087-1098. [CrossRef]

46. Lim, G.-O.; Jang, S.-A.; Bin Song, K. Physical and antimicrobial properties of Gelidium corneum/nano-clay composite film containing grapefruit seed extract or thymol. J. Food Eng. 2010, 98, 415-420. [CrossRef]

47. Mir, S.A.; Dar, B.N.; Wani, A.A.; Shah, M.A. Effect of plant extracts on the techno-functional properties of biodegradable packaging films. Trends Food Sci. Technol. 2018, 80, 141-154. [CrossRef]

48. Riahi, Z.; Priyadarshi, R.; Rhim, J.-W.; Bagheri, R. Gelatin-based functional films integrated with grapefruit seed extract and TiO2 for active food packaging applications. Food Hydrocoll. 2021, 112, 106314. [CrossRef]

49. Shankar, S.; Teng, X.; Li, G.; Rhim, J.-W. Preparation, characterization, and antimicrobial activity of gelatin/ZnO nanocomposite films. Food Hydrocoll. 2015, 45, 264-271. [CrossRef]

50. Bodini, R.; Sobral, P.; Favaro-Trindade, C.S.; Carvalho, R. Properties of gelatin-based films with added ethanol-propolis extract. LWT 2013, 51, 104-110. [CrossRef]

51. Ezati, P.; Priyadarshi, R.; Bang, Y.-J.; Rhim, J.-W. CMC and CNF-based intelligent pH-responsive color indicator films integrated with shikonin to monitor fish freshness. Food Control. 2021, 126, 108046. [CrossRef]

52. Priyadarshi, R.; Kumar, B.; Rhim, J.-W. Green and facile synthesis of carboxymethylcellulose/ZnO nanocomposite hydrogels crosslinked with Zn2+ ions. Int. J. Biol. Macromol. 2020, 162, 229-235. [CrossRef]

53. Wan, A.; Xu, Q.; Sun, Y.; Li, H. Antioxidant Activity of High Molecular Weight Chitosan and N,O-Quaternized Chitosans. J. Agric. Food Chem. 2013, 61, 6921-6928. [CrossRef] [PubMed]

54. Priyadarshi, R.; Riahi, Z.; Rhim, J.-W. Antioxidant pectin/pullulan edible coating incorporated with Vitis vinifera grape seed extract for extending the shelf life of peanuts. Postharvest Biol. Technol. 2022, 183, 111740. [CrossRef]

55. Alizadeh-Sani, M.; Mohammadian, E.; McClements, D.J. Eco-friendly active packaging consisting of nanostructured biopolymer matrix reinforced with $\mathrm{TiO} 2$ and essential oil: Application for preservation of refrigerated meat. Food Chem. 2020, $322,126782$. [CrossRef] [PubMed]

56. Ellis, D.I.; Goodacre, R. Rapid and quantitative detection of the microbial spoilage of muscle foods: Current status and future trends. Trends Food Sci. Technol. 2001, 12, 414-424. [CrossRef]

57. Panagou, E.Z.; Papadopoulou, O.; Carstensen, J.M.; Nychas, G.-J.E. Potential of multispectral imaging technology for rapid and non-destructive determination of the microbiological quality of beef filets during aerobic storage. Int. J. Food Microbiol. 2014, 174, 1-11. [CrossRef]

58. Camo, J.; Beltrán, J.A.; Roncalés, P. Extension of the display life of lamb with an antioxidant active packaging. Meat Sci. 2008, 80, 1086-1091. [CrossRef]

59. Saedi, S.; Shokri, M.; Priyadarshi, R.; Rhim, J.-W. Carrageenan-Based Antimicrobial Films Integrated with Sulfur-Coated Iron Oxide Nanoparticles (Fe3O4@SNP). ACS Appl. Polym. Mater. 2021, 3, 4913-4923. [CrossRef] 